\author{
Leticia Pereira, Roberto Martins and M aria Marques
}

\title{
MULTIBLOCK MICROSTRUCTURE USING A BINARY SYSTEM OF METALLOCENE CATALYSTS WITH DIETHYL ZINC AS TRAN SFER AGENT
}

\author{
Universidade Federal do Rio de Janeiro, Instituto de M acromoleculas Eloisa M ano, \\ IM A-UFRJ . Cidade Universitaria. Av. Horacio M acedo, 2.030. Centro de Tecnologia. Bloco J. \\ Rio de Janeiro.RJ.Brasil; fmarques@ima.ufrj.br
}

Received: October 11, 2012 / Revised: November 05, 2012 / Accepted: December 25, 2012

() Pereira L., Martins R., Marques M., 2013

\begin{abstract}
The aim of this study was to synthesize ethylene-hexene copolymers of the type LLDPE using a combination of metallocene binary catalysts (Cat 1: $\mathrm{Cp}_{2} \mathrm{ZrCl}_{2}$ and Cat 2: $\left.\mathrm{Et}\left(\mathrm{IndH}_{4}\right)_{2} \mathrm{ZrCl}_{2}\right)$, where each catalyst has different microstructural control capacities. The effect of diethyl zinc (DEZ) concentration as a chain shuttling agent (CSA) was evaluated in parameters such as catalytic activity, as well as thermal properties, comonomer content incorporated into the polymer chain, crystal structure, and also dynamic mechanical properties of the obtained copolymers. The results showed that, opposite to the behavior of the catalyst mixtures, DEZ promoted an increase in the polymerization activity with the isolated catalysts. Furthermore, CSA provided the increase of the rigid segments in the copolymer chain obtained with the binary catalyst.
\end{abstract}

Keywords: polyethylene, ethylene copolymer, chain shuttling agent, binary catalyst, metallocene.

\section{Introduction}

Polyolefins are considered to be the most imortant class of synthetic polymers, because of high volume of products consumed annually. The world consumption was around 100 million tons in 2005, and in 2007 the world consumed about 260 million tons of plastics ( $c a .1 .5$ times the consumption of steel by volume), polyolefin was among these 110 million tons [1-3].

The catalysts contribute to greater efficiency in almost all production processes of most materials from chemical industry. The polyolefin industry is one of the greatest examples of success in the field of catalysis [4]. In fact, the discovery of catalysts that operate in the synthesis of polyolefins with high activity has been the most relevant factor for the development of new polymers that have caused great impact among consumers due to its countless benefits and its various features and applications [5].

The new technology by Dow Chemical allows the production of new multiblock copolymers, employing a system containing two catalysts (single site) with different capacities of the comonomer incorporation, or with different stereoselectivity. A chain shuttling agent (CSA) is added to the system which function is to promote the exchange between the alkyl growing chains linked to both catalysts fed into the reactor. This process requires a catalyst (Cat 1) with high selectivity to ethylene, which forms a hard sequence, and a second catalyst (Cat 2) with high incorporation of comonomer that makes amorphous chains, forming a soft polymer [6-10].

This multiblock copolymer consists in blocks of crystalline ethylene-octene (with low amounts of comonomer and high melting temperature), alternating with blocks of amorphous ethylene-octene (comonomer with high quantity and low melting temperature) $[11,12]$. The soft blocks provide elasticity at low temperatures, while the rigid blocks provides resistance to high temperatures. Therefore, the flexibility of random copolymer should be achieved with simultaneous improvement of strength and elasticity. Thus this new technology allows independent control of properties such as modulus and heat resistance [6-12].

The present work shows the synthesis of ethylenehexene copolymer using a binary mixture of metallocene catalysts (Cat 1: $\mathrm{Cp}_{2} \mathrm{ZrCl}_{2}$ and Cat 2: $\mathrm{Et}\left(\mathrm{IndH}_{4}\right)_{2} \mathrm{ZrCl}_{2}$ ) and diethyl zinc (DEZ) as CSA in order to evaluate the influence of DEZ concentration on thermal properties, crystallinity and dynamic mechanical behavior of copolymers. Even if both catalysts tend to incorporate the comonomer in similar extent, each catalyst provides a proper microstructure of the polymer chain, with different sequence size distribution of monomers in the backbone, which will result in distinct crystalline characteristics [13]. 
Owing to the fact that each of the chosen catalyst synthesizes copolymers with different microstructure, and therefore, different crystalline degree, the aim of this work was to synthesize copolymers with both microstructure characteristics in the same polymer chain.

\section{Experimental}

All substances that are sensitive to moisture and oxygen were handled under inert nitrogen atmosphere using Schlenk techniques.

\subsection{M aterials}

The monomer ethylene origin at Praxair Industrial Gases, purity polymerization degree gone through the purification process consisting in processing columns of molecular sieves $3 \AA$ and columns of copper catalyst for the removal of impurities. The comonomer 1-hexene origin at RioPol, degree of polymerization, dried over molecular sieves $4 \AA$. The catalyst $\mathrm{Cp}_{2} \mathrm{ZrCl}_{2}$ [bis(cyclopentadienyl) zirconium dichloride] origin $\mathrm{PG}$ Aldrich BN 10715, purity for synthesis was identified as Cat 1; the second catalyst was $\mathrm{Et}\left(\mathrm{IndH}_{4}\right) \mathrm{ZrCl}_{2}$ [ethylidene bis(tetrahydro indenyl) zirconium dichloride] origin Witco TA 02849 , degree of purity, for synthesis identified as Cat 2. The cocatalyst methylaluminoxane (MAO, Chemtura $10 \mathrm{wt} \%$ toluene, $0.8854 \mathrm{~g} / \mathrm{ml}$ ) in the solution was used as received. The toluene had origin at Ipiranga petrochemical with a degree purity: commercial, distilled under sodium/benzophenone under an atmosphere of dry nitrogen.

\subsection{Copolymerization}

The copolymers of ethylene/hexene were carried out in jacketed Büchi glass reactor of $1000 \mathrm{ml}$ of capacity, equipped with a mechanical stirrer and thermostatic bath for temperature control. Reactions were performed in a distilled toluene, with ethylene pressure $2.6 \cdot 10^{5} \mathrm{~Pa}$ at $353 \mathrm{~K}$. The amount of cocatalyst methylaluminoxane (MAO) was $2.9 \mathrm{ml}$, the ratio $\mathrm{Al} / \mathrm{Cat} 1$ was 880 . For Cat 2 the amount was $8.7 \mathrm{ml}$ of $\mathrm{MAO}$, ratio $\mathrm{Al} / \mathrm{Cat} 2$ was 1015 for $100 \mathrm{ml}$ of toluene. The amount of hexene introduced in the reactor was the same for polymerization with the isolated catalysts, this is, $10 \mathrm{~g}(15 \mathrm{ml})$, to ensure that the comonomer conversion was low and therefore, the composition of the comonomer in the reaction medium did not sharply decrease. Different concentrations of DEZ were used in polymerizations with each catalyst system chosen. In the reactions with a mixture of catalysts, the volumes of toluene and hexene were 200 and $30 \mathrm{ml}$, respectively. All reactions were performed in duplicate.

\subsection{Catalytic Activity}

The activity was calculated in tons of polymer produced per mol of transition metal, mol of ethylene hour (ton/molMe $\cdot \mathrm{molE} \cdot \mathrm{h})$, where: molMe $=$ number of moles of the catalyst $(\mathrm{Me}=\mathrm{Zr})$ in the reaction; $\mathrm{molE}=$ number of moles of ethylene in the reaction, the reaction time was $30 \mathrm{~min}$. The concentration of ethylene dissolved in the reaction medium was calculated using the state equation, considering the values of critical temperature, critical pressure and compressibility factor $(w)$. The concentration of ethylene in toluene is $0.135 \mathrm{M}$ at $2.6 \cdot 10^{5} \mathrm{~Pa}$ and $353 \mathrm{~K}$.

\subsection{Characterization}

The copolymers were characterized by density measurements using the pycnometer method; analysis by infrared and near infrared absorption spectroscopy (FTIR) to determine the comonomer incorporation, differential scanning calorimetry (DSC) was used to determine the thermal properties and degree of crystallinity; X-ray diffraction analyses were performed to study the materials crystallinity; dynamic mechanical analysis (DMA) was also employed to evaluate storage $(E)$ and loss $\left(E^{\prime \prime}\right)$ moduli of the copolymers produced, as well as damping factor (tan delta) and glass transition temperature $\left(T_{g}\right)$.

\section{Results and Discussion}

Ethylene-hexene copolymerization was performed using Cat $1\left(\mathrm{Cp}_{2} \mathrm{ZrCl}_{2}\right)$ and Cat $2\left(\mathrm{Et}\left(\mathrm{IndH}_{4}\right)_{2} \mathrm{ZrCl}_{2}\right)$ either isolated and as the binary system with and without the addition of $\mathrm{ZnEt}_{2}$ as the chain transfer agent and the results are presented in Table 1 .

As it can be observed, the chain shuttling agent (DEZ) promoted an increase in activity for both isolated catalysts, especially with the system $\mathrm{Cp}_{2} \mathrm{ZrCl}_{2}$ (Cat 1), which activity increased four times, giving a higher response to DEZ. However, this trend was not detected in the catalyst mixture (Cat $1+$ Cat 2), in which it was noticed that the activity decreased with the addition of $\mathrm{ZnEt}_{2}$, similarly to that witnessed by Martins et al. [14]. The activity studied in binary systems with alkyl compound has not been fully understood, since Teranishi et al. [15] and Chien et al. [16] have observed the increased activity in a mixture of catalysts in the presence of trimethylaluminium (TMA) and triisobutylaluminium (TIBA), respectively. However, Bastos et al. [17] reported a decrease in the catalytic activity with another binary system also using TIBA.

The reason for the increase or decrease of the catalyst efficiency was proposed by Meurs et al. [18]. According to the authors, the polymer chain terminated by the chain transfer with the metal alkyl compound can 
remain coordinated with this metal, resulting in decreased activity. However, in binary systems, this chain can reversibly react with a second catalytic center resulting in further growing of the polymer chain, which would lead to an increase in the catalyst activity [6-7, 10]. However, this mechanism does not fully explain the results observed in the binary catalytic system of this work. It is suggested that the transfer reaction of the polymer chain from the metal compound to the catalyst centers of Cat 1 , which has lower activity, promotes the decline in the overall activity of the binary catalysts with the introduction of DEZ.

Table 1

Characterization of copolymers

\begin{tabular}{|l|c|c|c|c|c|c|c|c|}
\hline \multicolumn{1}{|c}{ Catalyst } & $\begin{array}{c}{[\mathrm{Zn}] /\left[\mathrm{C}_{2} \mathrm{H}_{4}\right] \cdot 10^{3},} \\
\mathrm{M}\end{array}$ & $\begin{array}{c}\text { Yield, } \\
\mathrm{g}\end{array}$ & $a^{*}$ & $d$ & $\begin{array}{c}\text { Conv. } H, \\
\text { wt } \%\end{array}$ & $\begin{array}{c}T_{m}, \\
\mathrm{~K}\end{array}$ & $\begin{array}{c}X_{c}, \\
\%\end{array}$ & $T_{c}, \mathrm{~K}$ \\
\hline $\begin{array}{l}\mathrm{Cp}_{2} \mathrm{ZrCl}_{2} \\
(\mathrm{Cat} 1)\end{array}$ & - & 10.1 & 29 & - & 5 & 376 & 9 & 365 \\
\hline $\left.\begin{array}{l}\mathrm{Et}(\mathrm{IndH} \\
(\mathrm{Cat} 2)\end{array}\right) \mathrm{ZrCl}_{2}$ & 0.5 & 45.6 & 131 & 0.93 & 5 & 386 & 27 & 377 \\
\hline \multirow{3}{*}{$\mathrm{Cp}_{2} \mathrm{ZrCl}_{2}+\mathrm{Et}\left(\mathrm{IndH}_{4}\right)_{2} \mathrm{ZrCl}_{2}$} & - & 45.6 & 51 & 0.93 & 5 & 398 & 38 & 386 \\
\cline { 2 - 10 } & 0.5 & 52.6 & 59 & 0.93 & 4 & 397 & 46 & 387 \\
\cline { 2 - 10 } & - & 91.0 & 74 & 0.91 & 4 & 395 & 50 & 385 \\
\hline
\end{tabular}

Polymerization conditions: temperature $353 \mathrm{~K}$, ethylene pressure $2.6 \cdot 10^{5} \mathrm{~Pa}$, toluene 100 or $200 \mathrm{ml}$ for mixtures; Cat $1=5.0 \cdot 10^{-6} \mathrm{~mol}$; Cat $2=1.3 \cdot 10^{-5} \mathrm{~mol}$; MAO: Al $/ \mathrm{Cat} 1=880$, $\mathrm{Al} / \mathrm{Cat} 2=1015$, time $30 \mathrm{~min}$, [1-hexene] $0.38 \mathrm{M}$;

$* a$ - activity: ton polymer/molM-molE.h; $d$-density; $H$ - amount of hexene incorporated; Conv. $H$ - amount of hexene conversion; $T_{m}$ : melting temperature; $\mathrm{X}_{\mathrm{c}}$ - crystallinity degree; $T_{c}$ - crystallization temperature; $[\mathrm{DEZ}]=0.5 \cdot 10^{-3} \mathrm{M}$ (low amount-L) and [DEZ] $=2.5 \cdot 10^{-3} \mathrm{M}$ (high amount-H).

In regard to the incorporation of the comonomer, it is noted that there was no change in the content of 1-hexene incorporated in the chain for all synthesized polymers produced with the isolated catalysts, both with and without DEZ, although the thermal properties were different for the synthesized copolymers. Cat 2 produced copolymer with higher melting temperature $\left(T_{m}\right)$, crystalliation temperature $\left(T_{c}\right)$ and degree of crystallinity $\left(X_{c}\right)$. This means that the copolymers synthesized by both catalysts differed in the chain microstructure, this is, Cat 2 produces polymers with longer ethylene sequences and therefore, increases $T_{m}$ and crystallinity, although with the same amount of hexene as the copolymer produced with Cat 1 .

On the other hand, for the copolymer obtained by mixing both catalysts and introducing high concentration of DEZ $\left(2.5 \cdot 10^{-3} \mathrm{M}\right)$, the incorporation of 1-hexene was $10 \mathrm{~mol} \%$ and the thermal properties of the polymer like $T_{m}, T_{c}$ and $X_{c}$, have not decreased when compared with other copolymers (Table 1). As already known, the incorporation of $\alpha$-olefins in the polymer chain hinders its packaging at the time of crystallization, due to defects caused by the comonomer in the chain regularity. Thus, there is a commitment in the formation of spherulites, forming less perfect crystals.

Therefore, high incorporation of comonomer in the polymer chain promotes the reduction of melting temperatures and crystallinity content of the material and results in peak broadening of the DSC thermograms [19].
The fact of the copolymer obtained by the catalyst mixture possess higher thermal properties was unexpected, since the high incorporation of comonomer should decrease thermal properties and degree of crystallinity of polymers. However, the lack of variation in these parameters could indicate the formation of a multiblock sequences in the polymer chains; with blocks of each microstructure characteristic of every copolymer synthesized by each one of the catalysts.

Researches on microstructure of ethylene-hexene copolymer revealed that low levels of 1-hexene incorporated in the backbone promoted a wide distribution of sequence lengths of ethylene in the polymer chain, resulting in larger crystals with thicknesses in the regions of long sequences of ethylene. However, in the copolymers with high comonomer content, the units of 1-hexene interrupt the sequences of ethylene, forming smaller crystals and decreasing the melting temperature [20]. Therefore, it was expected that there would be a decrease in both $T_{m}$ and $X_{c}$ in the copolymers with higher concentrations of incorporated 1-hexene. As this effect did not occur, it is believed to be due to formation of multiblock containing long sequences of ethylene. The melting temperatures of these chain-shuttling copolymers were also indicative of their unusual microstructure. In polyethylene-based materials, comonomers are introduced to disrupt crystallinity and to provide elasticity to the resulting polymer products [21]. 
Moreover, we postulate that the rate of chain transfer from $\mathrm{Zn}$ is higher for Cat 2 than for Cat 1, since the thermal properties of the copolymer obtained with the binary system are more similar to that produced by Cat 2 .

The DSC endotherms in Fig. 1 show slight broadening of the calorimetric curve with the addition of DEZ, as well as presented shoulder around $388 \mathrm{~K}$ at low amount of DEZ (L), characterizing the formation of crystals of different sizes due to the different sequences of monomers incorporated into the polymer chain. Interestingly, copolymers with binary catalyst exhibit endotherms very different from those obtained in polymers synthesized with the isolated catalysts (Fig. 2), which shows that it is not a mixture of copolymers but quite different microstructures of macromolecular chains from those obtained with the isolated catalysts. The endotherms in these cases are much narrower. It is noticed that, even in binary mixtures without the addition of DEZ, the DSC profiles changed in relation to the copolymers synthesized with the isolated catalysts. Possibly, chain transfer reactions occurred under polymerization conditions, by means of the residual TMA contained in MAO.

However, in both polymers from the catalytic mixtures an endotherm broadening of the curves was observed and, as expected, the decrease in $T_{m}, T_{c}$ and $X_{c}$.

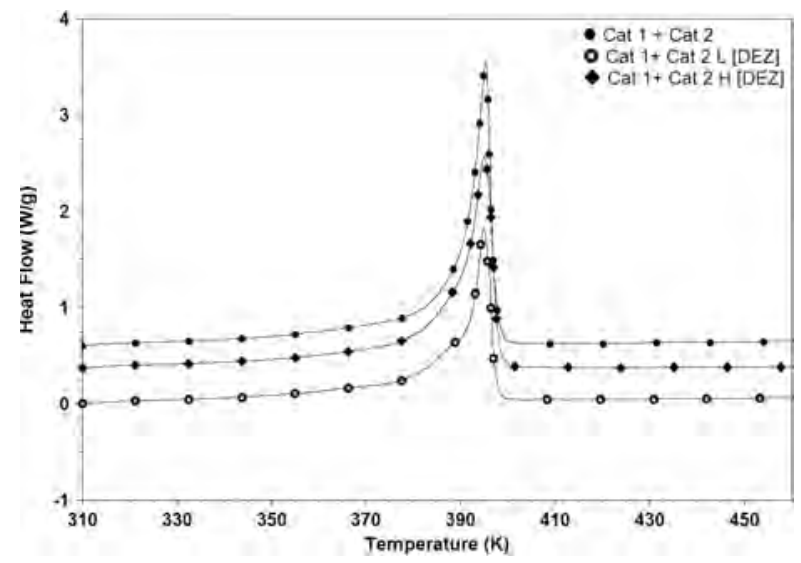

Fig. 1. DSC endotherms of copolymers synthesized by binary systems: L [DEZ] - low amount of DEZ, H [DEZ] - high amount of DEZ, Cat $1+$ Cat 2 - without DEZ

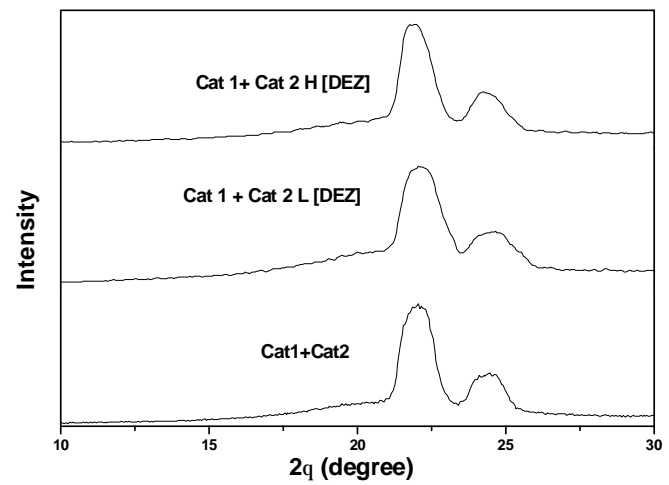

Khariwala et al. [12] in the study of crystallization kinetics of multiblock copolymers of olefins (OBC) reported that the small peak shifting to lower temperatures may suggest reducing the amount of rigid blocks in the polymer chain, justified by the greater incorporation of comonomer and resulting in a decrease in melting temperature $\left(T_{m}\right)$.

$\mathrm{X}$-Ray diffraction also provided valuable informaion regarding the proposed formation of multiblocks. The XRD patterns of the copolymers obtained by the binary mixture with increasing amounts of DEZ are shown in Fig. 3, where the presence of peaks at $2 \theta$ around 21 and 24 degrees was observed, both characteristics of the crystalline structure of polyethylene, which are assigned as crystallographic planes (110) and (200), respectively. There was a slight broadening of the crystalline peaks and a small shift to lower angles with the increasing concentration of diethyl zinc, as well as reducing the amorphous halo, suggesting that the alkyl metal promoted the formation of rigid segments in the polymer chain. For the materials synthesized with two isolated catalysts (Fig. 4), there was a decrease in the amorphous halo in the presence of DEZ, suggesting that the compound favored the increase of the amount of rigid segments that give the material more crystalline characteristics.

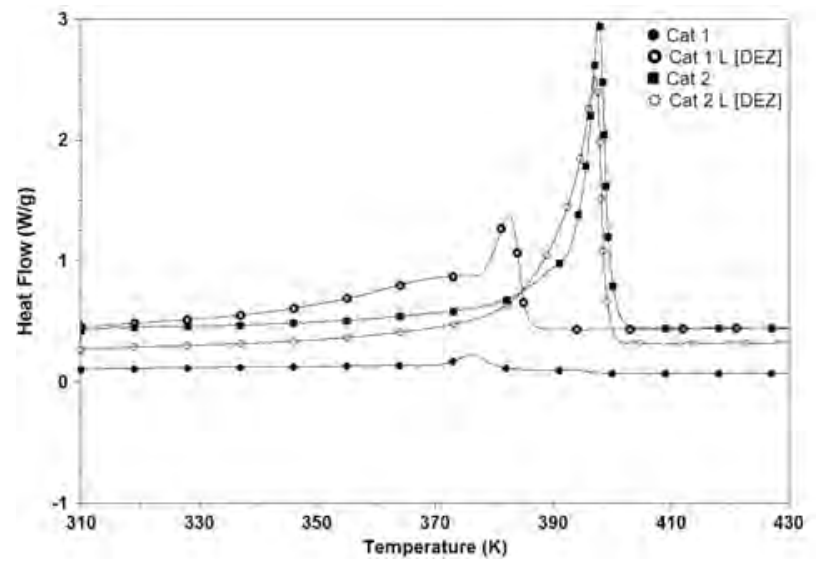

Fig. 2. DSC endotherms of copolymers synthesized by catalysts 1 and 2 isolated: L [DEZ] - low amount of DEZ

Fig. 3. X-ray diffraction of copolymers synthesized by binary system: L [DEZ] - low amount of DEZ, H [DEZ] - high amount of DEZ, Cat1+Cat2 - without DEZ 

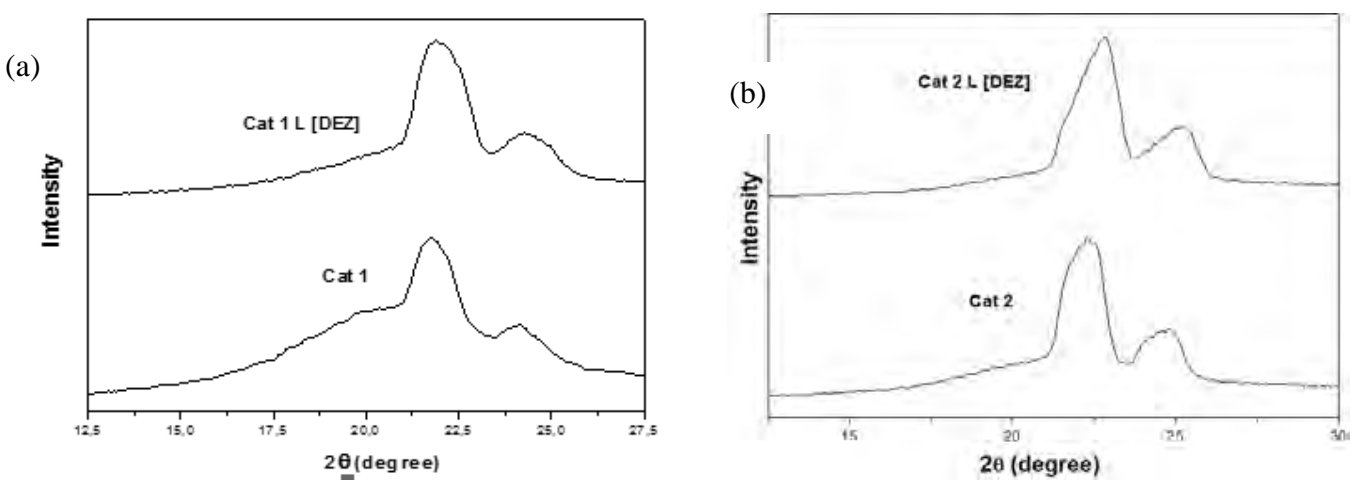

Fig. 4. X-ray diffraction of copolymers synthesized by catalysts 1 (a) and catalyst 2 (b) with low (L) amount of DEZ and without DEZ

Table 2

Dynamic mechanical properties of copolymers

\begin{tabular}{|c|c|c|c|c|c|c|c|c|}
\hline Catalyst & $\begin{array}{c}{[\mathrm{Zn}] /\left[\mathrm{C}_{2} \mathrm{H}_{4}\right] \cdot 10^{3},} \\
\mathrm{M}\end{array}$ & $\begin{array}{c}E^{\prime \prime}, \mathrm{MPa} \\
(158 \mathrm{~K})\end{array}$ & $\begin{array}{c}E^{\prime}, \mathrm{MPa} \\
(273 \mathrm{~K})\end{array}$ & $\begin{array}{c}E^{\prime \prime}, \mathrm{MPa} \\
(273 \mathrm{~K})\end{array}$ & $\begin{array}{c}T_{g}, \mathrm{~K} \\
E^{\prime}\end{array}$ & $\begin{array}{c}T_{g}, \mathrm{~K} \\
\tan \delta\end{array}$ & $T_{\alpha}, \mathrm{K}$ & $\begin{array}{c}\tan \delta \\
\max \beta\end{array}$ \\
\hline \multirow{2}{*}{ Cat 2} & - & 4460 & 1090 & 69.2 & 205 & 209 & 361 & 0.0903 \\
\hline Cat 1 + Cat 2 & 0.5 & 2289 & 599 & 33.0 & 195 & 197 & 354 & 0.0902 \\
\cline { 2 - 9 } & - & 6063 & 1574 & 140.3 & 206 & 221 & $\mathrm{Nd}$ & 0.0772 \\
\cline { 2 - 9 } & 0.5 & 3605 & 871 & 51.5 & 199 & 201 & 335 & 0.1078 \\
\cline { 2 - 9 } & 2.5 & 4164 & 1078 & 64.5 & 188 & 189 & 354 & 0.0865 \\
\hline
\end{tabular}

Notes: Nd- not determined; $\tan \delta \max \beta$ - damping factor at $T_{g} ; T_{\alpha}$ - temperature of alpha relaxation (crystalline phase)

Morphological studies have shown that long sequences of ethylene in the $\mathrm{OBC}$ rigid blocks can crystallize in the form of lamellar crystals with few defects and high melting temperatures, characterizing the rigid segments. The crystalline phase acts as the reinforcement since it forms physical nodes, connecting the elastomeric chains (soft segments) [19].

The results of dynamic mechanical analysis are shown in Table 2. For the copolymer obtained with the binary system, the damping factor in the range of the glass transition temperature $(\tan \delta \max \beta)$ increased with the addition of DEZ at low concentration, followed by a decrease at high concentration. This fact can be easily related to $E$ (elastic modulus), in which an inverse behavior was noticed. That is, polymerization at low concentration of compound DEZ promoted the increasing content of the chain relaxation mechanism in the polymer chain and, consequently, the decrease of the elastic modulus, also decreasing the stiffness of the material. On the other hand, the increase of the amount of DEZ, faster chain shuttling may occur and the decrease in relaxation was observed at the same time as the increasing of the material stiffness (E'). When considering Cat 2 acting isolated, it was observed that DEZ did not provide practically any influence on the damping factor $(\tan \delta \max \beta)$ of the produced polymer. Regarding the moduli $\left(E\right.$ and $\left.E^{\prime \prime}\right)$, a significant decrease was observed in the copolymer obtained with the addition of DEZ in the reaction medium.
As for the beta relaxation, the curve of $E^{\prime \prime}$ showed a peak corresponding to $T_{g}$ of the copolymers, where it can be noticed that $T_{g}$ of the copolymers decreased with the addition of DEZ in the reaction medium in relation to that synthesized without this agent. This may indicate that there are long sequences of ethylene in the copolymer (synthesized with DEZ), which leads to lower values of $T_{g}$.

In the binary system, especially in the copolymers synthesized at high concentration of DEZ, it appears that the temperature of alpha relaxation has increased (signal intensity increased from 0.1947 to 0.1992 ); therefore, the content of rigid blocks in the copolymer chain has increased, as this behavior should be related to the increase of rigid blocks in the polymer chain. On the other hand, with the increase in DEZ content both intensity and relaxation temperature $\left(T_{\alpha}\right)$ of the polymer have not varied, compared to the polymers produced with the isolated Cat 2 at low amount of DEZ (around $354 \mathrm{~K}$ ).

Regarding the beta relaxation, there is clearly a variation in the temperature of this relaxation, with a significant decrease of the copolymer $T_{g}$ obtained with the binary mixture with the addition of high concentration DEZ. At the same time, there was an increase in the storage modulus $E$, indicating that the size of ethylene sequences has increased.

According to Wang et al. [19], the alpha relaxation occurs at higher temperature and corresponds to the relaxation of amorphous molecular segments in the 
crystalline phase of the polymer, being observed as a broad peak in the curve of $E^{\prime \prime}$ (loss modulus) - T. The curve of $E^{\prime \prime}-\mathrm{T}$ corresponding to the behavior of the polymers synthesized in this work (Fig. 5) showed a peak related to $T_{g}$ of copolymers at around $203 \mathrm{~K}$. It can be noted that the copolymers $T_{g}$ decreased with the addition of low amount of DEZ in relation to the those synthesized without this agent, while the damping factor $(\tan \delta \max )$ related to the amorphous phase increased. This shows once again that there are long sequences of ethylene in the copolymer (with DEZ), which leads to an increase in $E^{\prime}$, although the amount of comonomer incorporated in the copolymer resulted similar to that obtained without the addition of DEZ. Moreover, the addition of higher amount of DEZ in the polymerization medium led to the increase in $E$ ', $\tan \delta \max$ and $E^{\prime}$, increasing the stiffness of the sample.

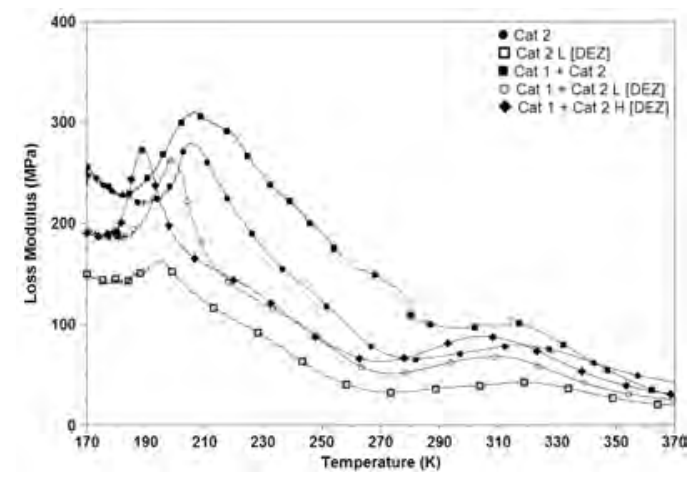

Fig. 5. Loss moduli of copolymers

\section{Conclusions}

The addition of diethyl zinc (DEZ) promoted increased activity in polymerization of ethylene-hexene with the isolated catalysts employed, although the behavior of catalytic mixtures was inverted. Moreover, there was not a significant variation in 1-hexene incorporation with the addition of DEZ. In the crystal structure of the obtained polymers, the DEZ provided the increase of rigid segments in the copolymer chain, showing that there was a decrease of the amorphous halo and an increased intensity of the crystalline peaks. Regarding to the dynamic mechanical properties, the chain shuttling agent has promoted the reduction of rigid segments in the copolymers chains obtained by catalytic mixtures, but at high concentrations of DEZ there was an increase of the material moduli. There was a significant decrease in $T_{g}$ of the copolymer with the addition of higher concentration of DEZ, indicating that the size of the blocks of ethylene has increased.

\section{Acknowledgments}

The authors thank CAPES, CNPq and Petrobras.

\section{References}

[1] Makio H., Terao H., Iwashita A. and Fujita T.: Chem. Rev., 2011, 111, 2363.

[2] Mitani M., Saito J., Ishii S-I. et al.: Chem. Rec., 2004, 4,137.

[3] Qiao J., Guo M., Wang L. et al.: Polym. Chem., 2011, 8, 1611.

[4] Makio H. and Fugita T.: Accounts of Chem. Res., 2009, 42, 1532 .

[5] Makio H., Kashiwa N. and Fujita T.: Adv. Synthesis \& Catalysis, 2002, 344, 477.

[6] Gibson C.: Science, 2009, 312, 703.

[7] Tynys E., Eilertsen J., Seppällä J. and Rytter E.: J. Polym. Sci. A, 2007, 45, 1364.

[8] Alfano F., Boone H., Busico V. et al.: Macromolecules, 2007, 40, 7736 .

[9] Shan C. and Hazlitt L.: Macromol. Symposia, 2007, 257, 80.

[10] Kuhlman R. and Wenzel T.: Macromolecules, 2008, 41, 4090.

[11] Wang H., Khariwala D., Cheung W. et al.: Macromolecules, 2008, 40, 2852.

[12] Khariwala D., Taha A., Chum S. et al.: Polymer, 2008, 49, 1365.

[13] Zinck P.: Polym. Int., 2012, 61, 2.

[14] Martins R., Quinello L., Souza G. and Marques M.: Chem. Chem. Techn., 2012, 6, 153.

[15] Silveira F., Loureiro S., Galland G. et al.: J. Mol. Catal. A, 2003, 206, 389.

[16] Chien J., Iwamoto Y. and Rausch M.: J. Polym. Sci. A, 1999, 37, 2439 .

[17] Bastos Q. and Marques M.: J. Polym. Sci. A, 2005, 43, 263.

[18] Meurs M., Britovsek G., Gibson V. and Cohen S.: J. Am. Chem. Soc., 2005, 127, 9913.

[19] Wang H., Khariwala D., Cheung W. et al.: Macromolecules, 2008, 40, 2852.

[20] Zuo F., Hsiao B., Mehta A. et al.: Macromolecules, 2010, 43, 1922.

[21] Arriola D., Carnahan E., Hustad P. et al.: Science, 2006, 312, 714.

\section{МУЛЬТИБЛОЧНА МІКРОСТРУКТУРА З ВИКОРИСТАННЯМ ПОДВІЙНОЇ СИСТЕМИ МЕТАЛЛОЦЕНОВИХ КАТАЛІЗАТОРІВ З ДІЕТИЛОВИМ ЦИНКОМ ЯК АГЕНТУ ПЕРЕНОСУ}

Анотація. Синтезовано етилен-гексен кополімери типу LLDPE, використовуючи комбінацію металлоченових бінарних каталізаторів (Kat 1: $\mathrm{Cp}_{2} \mathrm{ZrCl}_{2}$ i Kat 2: Et (IndH $\left.\mathrm{H}_{4}\right)$ $2 \mathrm{ZrCl}_{2}$ ), де кожен каталізатор має різні можливості контолю мікроструктури. Проведено оиінювання ефекту діетилцинку (ДЕЦ) як ланцююгового човникового агента (ЛЧА) стосовно таких параметрів, як каталітична активність, теплових властивостей, вміст комономеру, включеного до полімерного ланцюга, кристалічної структури, а також динамічних механічних властивостей отриманих кополімерів. Показано, що на відміну від суміші каталізаторів, ДЕЦ сприяє збільшенню активності полімеризаиії з ізольованими каталізаторами. ЛЧА збільшує жорсткість сегментів в кополімерному ланиююі, отриманих за участю подвійного каталізатора.

Ключові слова: поліетилен, кополімер етилену, човниковий ланцюгговий агент, бінарний каталізатор, металлоцен. 